\title{
Natural Factors Influencing Blown Sand Hazards in Beijing
}

\author{
Lianyou Liu ${ }^{1, *}$, Peijun Shi ${ }^{2}$, Xia Hu${ }^{1}$, Tianke Liu ${ }^{1}$, Lanlan Guo ${ }^{1}$, Xiaoxiao Zhang ${ }^{1}$, Yan Tang ${ }^{1}$, Yanli Lv ${ }^{1}$, Bingyan \\ Sun ${ }^{1}$, Guoming Zhang ${ }^{1}$, Xiaoning Zhang', Weiqiang Zhang ${ }^{1}$, Yanyan Yang ${ }^{1}$, Jingpu Wang ${ }^{1}$, and Yiying Xiong ${ }^{1}$ \\ ${ }^{1}$ Key Laboratory of Environmental Change and Natural Disasters, Ministry of Education of China, Beijing Normal University, \\ Beijing 100875, China \\ ${ }^{2}$ State Key Laboratory of Earth Surface Processes and Resource Ecology, Beijing Normal University, Beijing 100875, China
}

\begin{abstract}
In this article, natural factors in the farmingpastoral ecotone that might have influenced the blown sand hazards in Beijing in 2000 are analyzed. In the farmingpastoral ecotone, blown sand activities took place primarily in springtime, during which 39.8 percent of the annual frequency of erosive winds above threshold occurred. The prevailing directions of the erosive winds were NNW, NW, NWW, and N, with frequencies of $47,20,13$, and 9 percent respectively. Sand entrainment and dust emission are influenced by erosive wind frequency, soil moisture, and land use and cover change. Favorable wind characteristics and a lasting drought in 1999 and 2000 may have produced ideal conditions for land surface desiccation, vegetation degradation, and land surface mobility and the occurrence of intense sand- and dust storms in Beijing.
\end{abstract}

Keywords Beijing, blown sand hazards, dust storms, sandstorms

\section{Introduction}

Sand entrainment and dust emission are coexistent phenomena during aeolian sand processes in arid areas. While the former has a close connection to sand flux, deserts, and desertification, the latter is regarded as one of the main dust contributors to the atmosphere, loess, and ocean floor strata (von Richthofen 1882; Liu 1985; Pye 1987). Yutu (Dust rain) and Chenmai (Dust haze) have been repeatedly recorded in Chinese historical accounts (Zhang 1982). It has been recognized that particulate matter with a diameter of $\leq 50 \mu \mathrm{m}$, especially $\leq 10 \mu \mathrm{m}\left(\mathrm{PM}_{10}\right)$, can deteriorate air quality and threaten human health more severely than sand particles (Stetler and Saxton 1996).

Accompanied by intense Siberian/Mongolian cold fronts, dust storms in eastern Asia move out of the Gobi and desert regions of China along varied southeastward trajectories (Duce et al. 1980; Qiu, Zeng, and Miao 2001). Beijing, the capital city of China, situated on the North China Plain to

\footnotetext{
* Corresponding author. E-mail: Iyliu@bnu.edu.cn
}

the east of semiarid areas, is noticeably affected by the southeastward encroachment of sand- and dust storms. In 2000, 12 sand- and dust storms struck Beijing and raised unprecedented public awareness (Shi et al. 2000).

The farming-pastoral ecotone in China is the transitional zone between the humid agricultural area and the arid and semiarid pastoral area. Due to insufficient rainfall and frequent droughts and strong winds in spring, as well as land degradation caused by overgrazing and extensive reclamation of the grassland for cultivation, wind erosion and related aeolian processes are extremely severe (Zhao et al. 1989; Zhu and Chen 1994). It has been recognized as one of the most ecologically fragile zones in China (Zhou and Zhang 1992). The high frequency of sand- and dust storms affecting Beijing is thought to be due to severe wind erosion and blown sand activities in this source area (Ye et al. 2000).

This article analyzes natural factors in the farmingpastoral ecotone that might have influenced the blown sand hazards in Beijing in 2000. The effect of vegetation on wind erosion and sand transport was evaluated through field measurements under different land cover conditions. The rate of wind erosion from different soil surfaces was determined through wind tunnel experiments. Data on precipitation and erosive wind above threshold velocity were collected to analyze the effect of climatic factors on blown sand activities. The possible effects of sand- and dust storms on air quality in Beijing are discussed.

\section{Materials and Methods}

The test soils for this study were collected from the farmingpastoral ecotone in China, including Zhenglan Banner and Huade County in Inner Mongolia, and Fengning County in Hebei Province. They are meadow Chernozem, steppe Chestnut, and fixed sandy soils. Five original soil samples were taken for each soil type. Organic matter and texture of the original soil samples were analyzed in the laboratory (Table 1). Wind tunnel experiments were conducted after eight weeks air-drying of the soil samples, in the Key 
Table 1. Basic properties of the tested soils

\begin{tabular}{|c|c|c|c|c|c|c|c|c|c|c|}
\hline Soil types & $\begin{array}{c}\text { Depth } \\
\text { (cm) }\end{array}$ & $\begin{array}{c}\text { Vegetation } \\
\text { coverage } \\
(\%)\end{array}$ & $\begin{array}{c}\text { Crust } \\
\text { thickness } \\
\text { (cm) }\end{array}$ & $\begin{array}{c}\text { Organics } \\
(\mathrm{g} / \mathrm{kg})\end{array}$ & $\begin{array}{c}\mathrm{CaCO}_{3} \\
(\mathrm{~g} / \mathrm{kg})\end{array}$ & $\begin{array}{c}\text { Water } \\
\text { content } \\
(\%)\end{array}$ & $\begin{array}{c}\text { Clay } \\
(\%)\end{array}$ & $\begin{array}{c}\text { Mean } \\
\text { diameter } \\
\text { (Ф) }\end{array}$ & $\begin{array}{c}\text { Soil } \\
\text { texture }\end{array}$ & $\begin{array}{c}\text { Parent } \\
\text { material }\end{array}$ \\
\hline \multirow[t]{2}{*}{ Chestnut } & $0-5$ & 35 & - & 18.39 & 108.4 & 1.61 & 13.78 & 5.55 & Loam & Sandy loess \\
\hline & $0-5$ & & - & 16.17 & 117.4 & 1.64 & 11.17 & 5.55 & & \\
\hline \multirow[t]{2}{*}{ Chernozem } & $0-5$ & 43 & - & 36.25 & 0.8 & 2.51 & 12.24 & 5.11 & \multirow[t]{2}{*}{ Sandy bam } & \multirow{2}{*}{$\begin{array}{l}\text { Volcanic } \\
\text { residues }\end{array}$} \\
\hline & $5-10$ & & - & 25.25 & 12.8 & 2.60 & 10.70 & 5.32 & & \\
\hline Fixed sandy soil & $0-5$ & 48 & $1-2$ & 11.37 & 37.2 & 0.79 & 2.00 & 3.21 & Sand & Blown sand \\
\hline
\end{tabular}

Laboratory of Desert and Desertification of the Chinese Academy of Sciences. Soil loss was determined by the difference in weight before and after each test, with a threecomponent balance. The effect of cultivation on sand entrainment and dust emission was also measured. Pitot tubes at $20 \mathrm{~cm}$ height measured free stream wind speed.

Fieldwork to observe 10 minute wind speeds and synchronous sand transport rates lasted for one month. Threshold wind speed was estimated with an instantaneous spinningcup anemometer and through direct observations of sand movement on dune surfaces. On the anemometer, wind velocity at 0.5 and $2 \mathrm{~m}$ heights above the ground was measured using an electrical generator driven by the spinning cups. All the anemometers were calibrated in a wind tunnel using standard pitot tubes before measurement in the field. Synchronous with the wind speed measurement, sand transport in every $2 \mathrm{~cm}$ segment up to $40 \mathrm{~cm}$ height was measured by two segmented sand traps stacked together (Yang, Di, and Huang 1991; Liu 1999). The sand transported during every 10 minute period was put in plastic bags and weighed with a $1 / 100 \mathrm{~g}$ portable manual scale to determine sand transport rates (three replicates). Through catch calibration of saltating sand in the wind tunnel, the efficiency of the sand trap was $70-90$ percent at wind velocities from 6 to $18 \mathrm{~m} \mathrm{~s}^{-1}$, and the trapping efficiency increased with the increase of wind speed. An average efficiency of 80 percent was used for calibrating the field-measured sand transport data. Because wind speed was mostly measured at $2 \mathrm{~m}$ height in the field by Chinese aeolian researchers, and for comparison with previous observation results, the relationship between wind speed and sand transport rate was explored by examining the calibrated wind speed at $2 \mathrm{~m}$ height and the calculated sand transport rates (Wu 1987; Qu et al. 2005).

In this research, 10 minute average sand transporting wind velocity data from the Fengning Weather Station in 2000 were collected for calculation of aeolian sand transport. The correlation between wind speed at $2 \mathrm{~m}$ in the field and wind speed at $10 \mathrm{~m}$ at the weather station was established. Dune sand transport potential and sand movement influenced by wind direction, speed, and frequency of the sand transporting winds were assessed.

\section{Results and Discussion}

\subsection{Influence of Vegetation Cover on Aeolian Sand Entrainment and Dust Emission}

Soil erosion is influenced by many land surface characteristics such as vegetation, crust, and pebble mulch. Some experiments indicated that the relationship between vegetation cover and wind erosion was in a pronounced negative exponential function (Fryrear 1985).

Field observations indicated that vegetation cover could significantly affect threshold wind velocity and sand transport rate. The threshold wind velocity is $6 \mathrm{~m} \mathrm{~s}^{-1}$ on mobile sandy surfaces with $V c$ (vegetation cover) $<5$ percent, $8 \mathrm{~m} \mathrm{~s}^{-1}$ on semifixed sandy surfaces with $V c$ 25-50 percent, and $10 \mathrm{~m} \mathrm{~s}^{-1}$ on fixed sandy surfaces with $V c>50$ percent. The relationships between sand transport rate $(q)$ and wind speed $(U)$ on mobile, semifixed, and fixed sandy surfaces are presented in Figure 1, and can be expressed by power functions:

Mobile dune: $\quad q=1.1 \times 10^{-3} \times U^{4.89} \quad R^{2}=0.95 \quad$ Eq. 1

Semifixed dune: $q=8.6 \times 10^{-8} \times U^{7.22} \quad R^{2}=0.95 \quad$ Eq. 2

Fixed dune: $\quad q=6.11 \times 10^{-6} \times U^{4.85} R^{2}=0.96 \quad$ Eq. 3

Sand transport rate increases with the increase of wind speed, and at a certain wind speed, it increases by one to two orders of magnitude with the increase of bare land ratio on fixed, semifixed, and mobile sand surfaces. This implies that, with the development of land desertification, sand entrainment and dust emission on mobile sand surfaces can take place more readily than on semifixed and fixed sand surfaces.

\subsection{Influence of Soil Surface Conditions on Wind Erosion}

Through wind tunnel experiments, the soil wind erosion modulus under both natural and disturbed conditions at different wind velocities was determined to provide information on soil natural erodibility and enhanced erodibility under cultivation. 

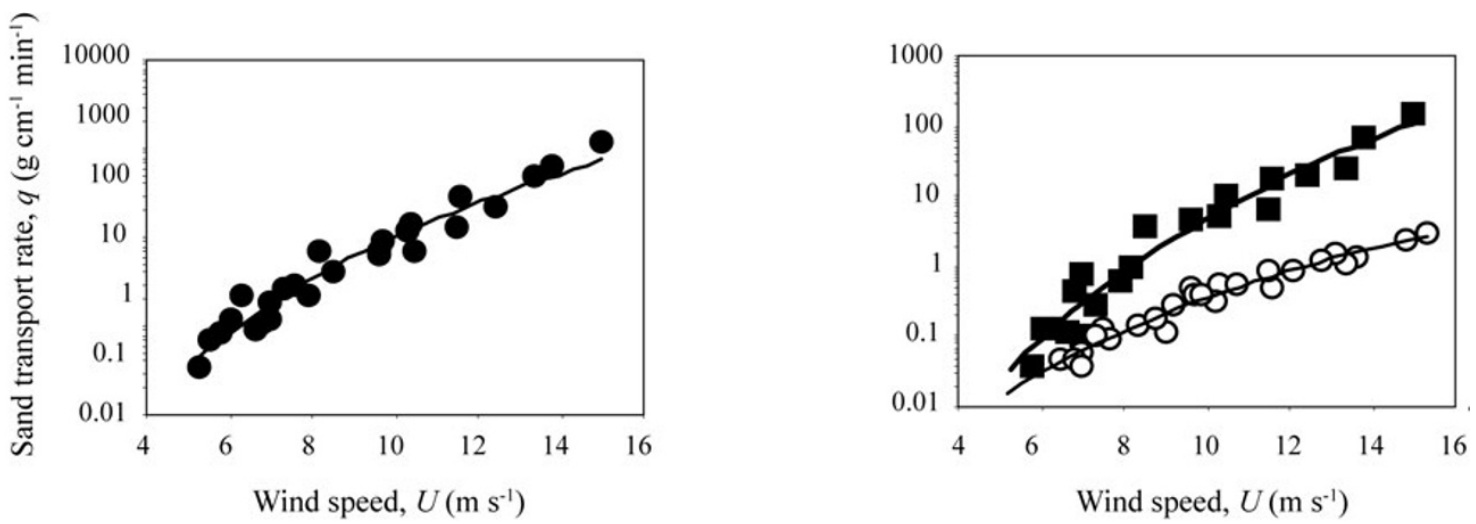

Figure 1. Relationship between sand transport rate $(q)$ and wind speed $(U)$ at $2 \mathrm{~m}$ height above the ground: $\bullet$ Mobile dune; - Semifixed dune; $\circ$ Fixed dune

The wind erosion modulus $\left(R_{\mathrm{a}}\right)$, defined as the amount of soil loss in a unit area and unit time, was used to express the intensity of wind erosion. The higher the $R_{\mathrm{a}}$, the more vulnerable the soil is to wind erosion. $R_{\mathrm{a}}$ values of different soils under identical wind speed and duration are listed in Table 2.

The relationship between wind erosion modulus and wind speed could be expressed as (Figure 2):

Chestnut:

$$
\begin{array}{ll}
R_{\mathrm{a}}=0.103 \mathrm{e}^{0.271 U} & R^{2}=0.98 \\
R_{\mathrm{a}}=0.627 \mathrm{e}^{0.174 U} & R^{2}=0.99 \\
R_{\mathrm{a}}=0.201 \mathrm{e}^{0.196 U} & R^{2}=0.89
\end{array}
$$

Chernozem:

Eq. 4

Eq. 5

The wind erosion modulus of all tested soils increased with the increase of wind speed. The average wind erosion modulus of Chestnut, Chernozem, and fixed sandy soil at the measured wind speeds was 28.5, 19.9, and $11.4 \mathrm{~g} \mathrm{~m}^{-2} \mathrm{~min}^{-1}$ respectively. This revealed that the Chestnut soil was the most vulnerable to wind erosion while the fixed sandy soil had the highest resistance. So it is important to protect vegetation in wind erosion areas to conserve soils and combat desertification.

Soil erosion by wind is a physical process affected by many variables. Due to excessive cultivation, the cultivation index in the semiarid area of northern China is above 40 percent, thus soil erosion on farmland is an important research aspect to evaluate the effect of cultivation on sand entrainment and dust emission.

Different soils possess different physical structures and chemical and textural compositions, thus have different

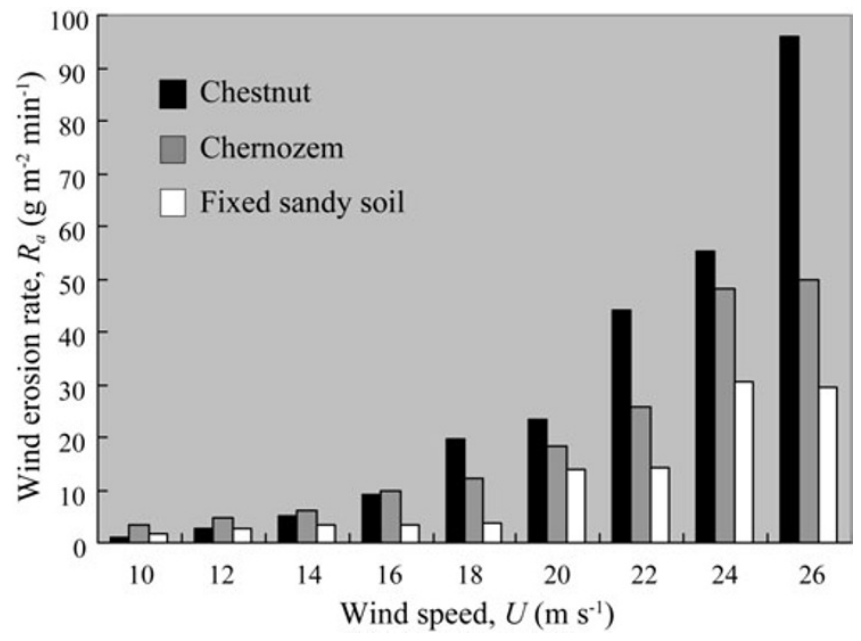

Figure 2. Relationship between wind speed and wind erosion modulus of original soils

sensibilities to cultivation disturbances. The wind erosion modulus of the tested soils after cultivation is shown in Table 3 and Figure 3.

After cultivation, the relationship between the wind erosion modulus and wind speed is exponential and can be expressed as:

Chestnut:

Chernozem:

Fixed sandy soil:

$$
\begin{array}{ll}
R_{\mathrm{a}}=0.02 \mathrm{e}^{0.40 U} & R^{2}=0.97 \\
R_{\mathrm{a}}=0.03 \mathrm{e}^{0.42 U} & R^{2}=0.98 \\
R_{\mathrm{a}}=0.07 \mathrm{e}^{0.49 U} & R^{2}=0.98
\end{array}
$$

\begin{tabular}{|c|c|c|c|c|c|c|c|c|c|c|}
\hline \multirow{2}{*}{\multicolumn{2}{|c|}{$R_{\mathrm{a}}$ values by soil type }} & \multicolumn{9}{|c|}{ Wind speed $\left(\mathrm{m} \mathrm{s}^{-1}\right) /$ Time (min) } \\
\hline & & $10 / 15$ & $12 / 10$ & $14 / 10$ & $16 / 8$ & $18 / 6$ & $20 / 4$ & $22 / 4$ & $24 / 2$ & $26 / 2$ \\
\hline \multirow{3}{*}{$\begin{array}{l}R_{\mathrm{a}} \\
\left(\mathrm{g} \mathrm{m}^{-2} \mathrm{~min}^{-1}\right)\end{array}$} & Chestnut & 1.03 & 2.70 & 5.04 & 9.20 & 19.60 & 23.37 & 43.94 & 55.37 & 95.87 \\
\hline & Chernozem & 3.30 & 4.73 & 6.14 & 9.86 & 12.30 & 18.36 & 25.68 & 48.30 & 49.98 \\
\hline & Fixed sandy soil & 1.53 & 2.63 & 3.36 & 3.44 & 3.86 & 13.98 & 14.28 & 30.44 & 29.46 \\
\hline
\end{tabular}

Eq. 8

Eq. 9

Table 2. $R_{\mathrm{a}}$ values of tested soils in original state ${ }^{\dagger}$

†Three replicates for each soil type. 
Table 3. Wind erosion modulus of the tested soils after cultivation ${ }^{\dagger}$

\begin{tabular}{|c|c|c|c|c|c|c|c|c|c|c|}
\hline \multirow{2}{*}{\multicolumn{2}{|c|}{$R_{\mathrm{a}}$ values by soil type }} & \multicolumn{9}{|c|}{ Wind speed $\left(\mathrm{m} \mathrm{s}^{-1}\right) /$ Time $(\mathrm{min})$} \\
\hline & & $10 / 15$ & $12 / 10$ & $14 / 10$ & $16 / 8$ & $18 / 6$ & $20 / 4$ & $22 / 4$ & $24 / 2$ & $26 / 2$ \\
\hline \multirow{3}{*}{$\begin{array}{l}R_{\mathrm{a}} \\
\left(\mathrm{g} \mathrm{m}^{-2} \mathrm{~min}^{-1}\right)\end{array}$} & Chestnut & 0.6 & 1.5 & 5.6 & 11.9 & 36.7 & 67.5 & 124.8 & 160.5 & 356.7 \\
\hline & Chernozem & 1.8 & 4.0 & 8.6 & 10.8 & 25.8 & 61.8 & 235.4 & 484.2 & 1073.8 \\
\hline & Fixed sandy soil & 5.6 & 31.2 & 50.1 & 178.2 & 629.0 & 1434.0 & 3631.0 & 9487.0 & 12573.0 \\
\hline
\end{tabular}

†Three replicates for each soil type.

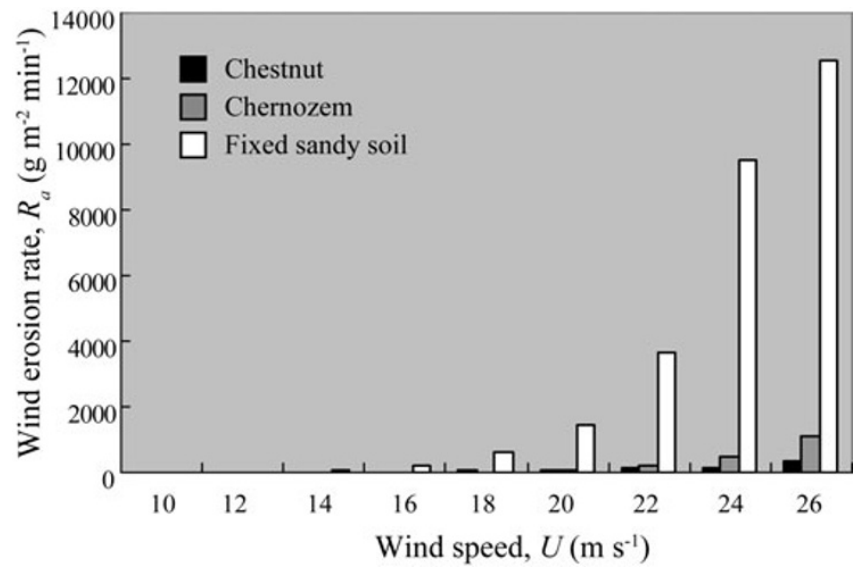

Figure 3. Relationship between wind speed and wind erosion modulus of soils after cultivation

The rate of soil erosion in all cultivated soils was intensified due to the breaking up of the soil structure and aggregate compositions. The average wind erosion modulus of Chestnut, Chernozem, and fixed sandy soils after cultivation was 85,212 , and $3113 \mathrm{~g} \mathrm{~m}^{-2} \mathrm{~min}^{-1}$ respectively, about 2,9 , and 272 times more than that under natural conditions.

\subsection{Wind Characteristics Influencing Sand Entrainment and Dust Emission}

\subsubsection{Erosive Wind Speed and its Frequency Distribution}

Aeolian sand entrainment and dust emission are closely connected to erosive wind speed above threshold $\left(U>6 \mathrm{~m} \mathrm{~s}^{-1}\right.$ in general). The correlation between wind speed at $2 \mathrm{~m}$ height in the field and wind speed at $10 \mathrm{~m}$ height at Fengning Weather Station could be expressed as:

$$
U_{2 \mathrm{~m}}=0.86 \times U_{10 \mathrm{~m}}-0.70 \quad R^{2}=0.95 \quad \text { Eq. } 10
$$

The whole-year 10 minute average sand transporting wind data at $10 \mathrm{~m}$ height were converted into near-bed wind velocity at $2 \mathrm{~m}$ above the ground. The erosive wind speed was between 6 and $13 \mathrm{~m} \mathrm{~s}^{-1}$ from 1991 to 2000 at the Fengning Weather Station, and its frequency decreased exponentially with the increase of wind speed (Figure 4). Strong winds responsible for sand- and dust storms have a low frequency and low-speed winds might have played a dominant role in sand blown activities.

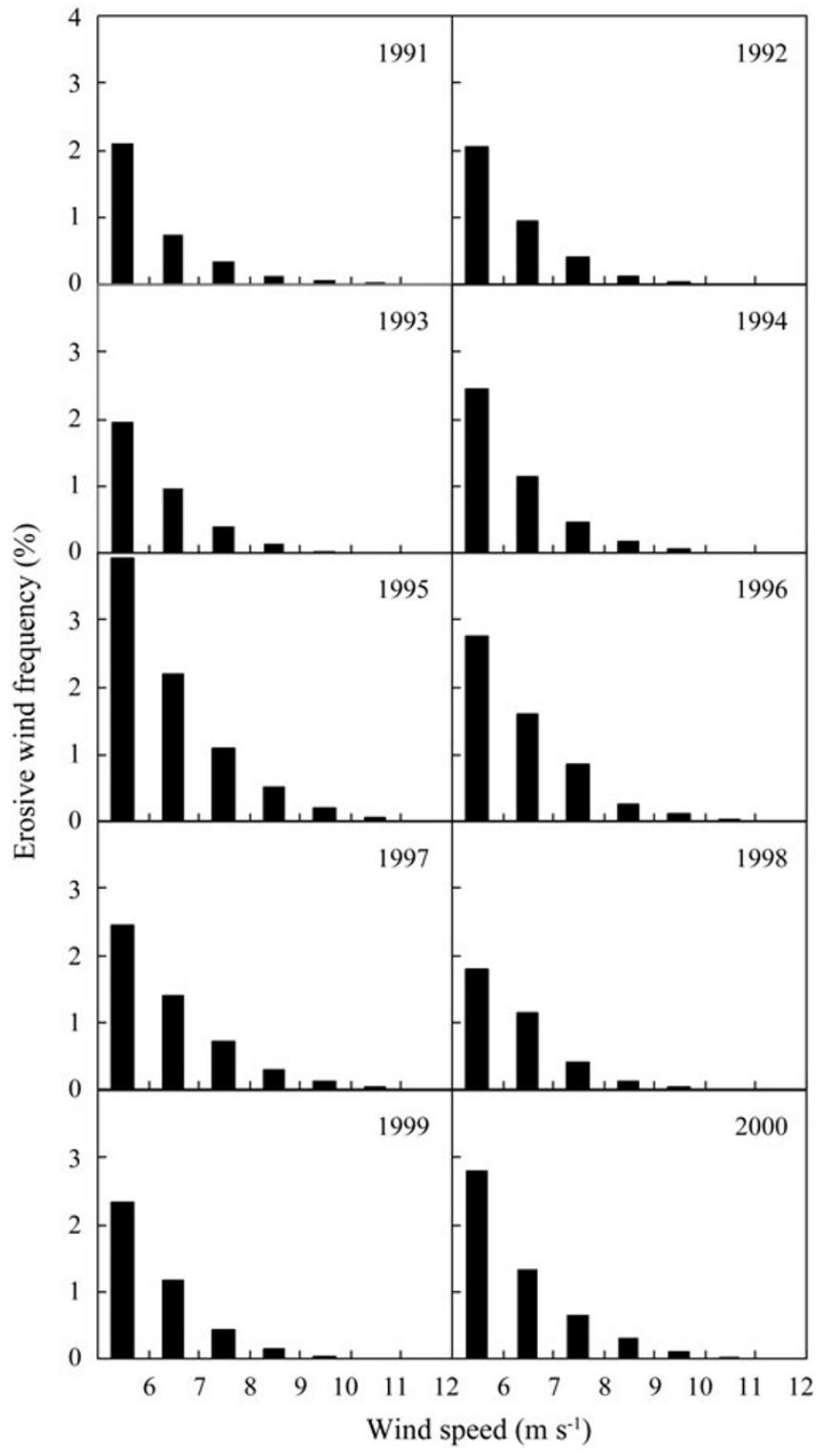

Figure 4. Distribution of erosive wind frequencies from 1991 to 2000 at Fengning, Hebei Province

\subsubsection{Interannual and Seasonal Changes of Erosive Wind Frequency}

The accumulative frequency of erosive winds from 1991 to 2000 was 4.6 percent on average, with a maximum of 7.95 
percent in 1995 and a minimum of 3.36 percent in 1991. It was 5.23 percent in 2000 , which ranked the third place in ten years (Figure 5). Although the accumulative frequencies in 1998, 1999, and 2000 were $3.48,4.10$, and 5.23 percent and the corresponding strong wind $\left(U>17 \mathrm{~m} \mathrm{~s}^{-1}\right)$ days were 16,20 , and 24 respectively, which created favorable wind conditions for blown sand activities, seen in the 10-year context, they cannot reasonably explain the outburst of sand- and dust storms in 2000.

The percentage of accumulative erosive wind frequency in every month from 1991 to 2000 is presented in Figure 6. It was 39.8 percent in spring, 5.4 percent in summer, 21.6 percent in autumn, and 33.2 percent in winter. Similar distributions occurred in every year (Figure 7). The springtime, with its high frequency of erosive winds, was consistent with the period of sand blown activities.

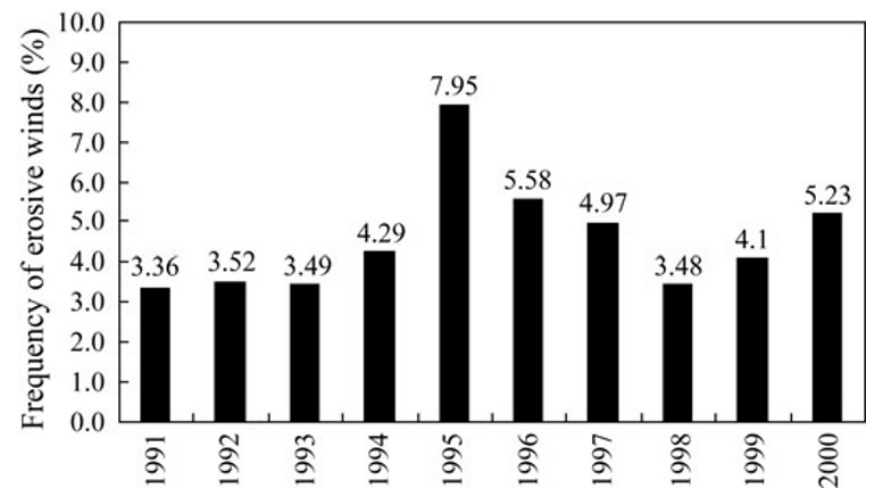

Figure 5. Accumulative frequency of erosive winds from 1991 to 2000 at Fengning, Hebei Province

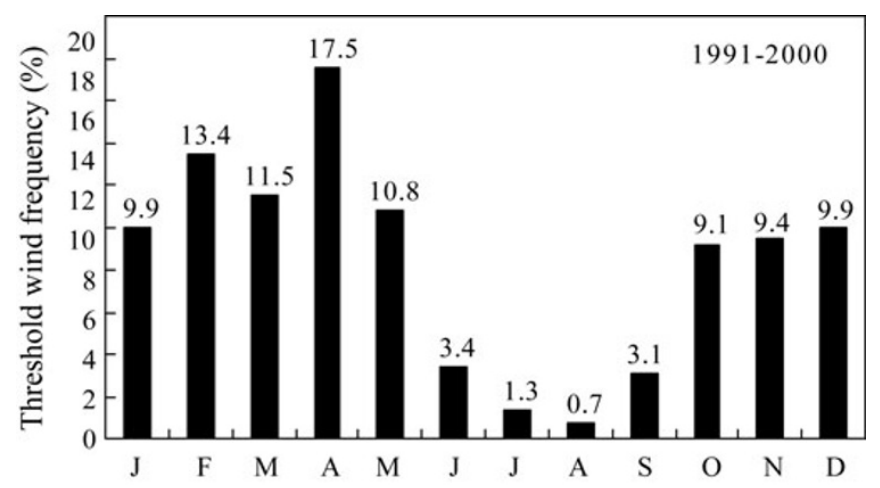

Figure 6. Accumulative erosive wind frequency in every month from 1991 to 2000 at Fengning, Hebei Province

\subsubsection{Prevailing Directions of Erosive Winds}

The frequency of erosive winds from 16 directions is presented in Figure 8. The prevailing wind direction was NNW, with a frequency of 46.73 percent. The secondary prevailing directions were NW, NWW, and N, with a frequency of 19.73, 12.81, and 9.18 percent respectively. Frequencies from all other directions were 11.55 percent in total. The prevailing

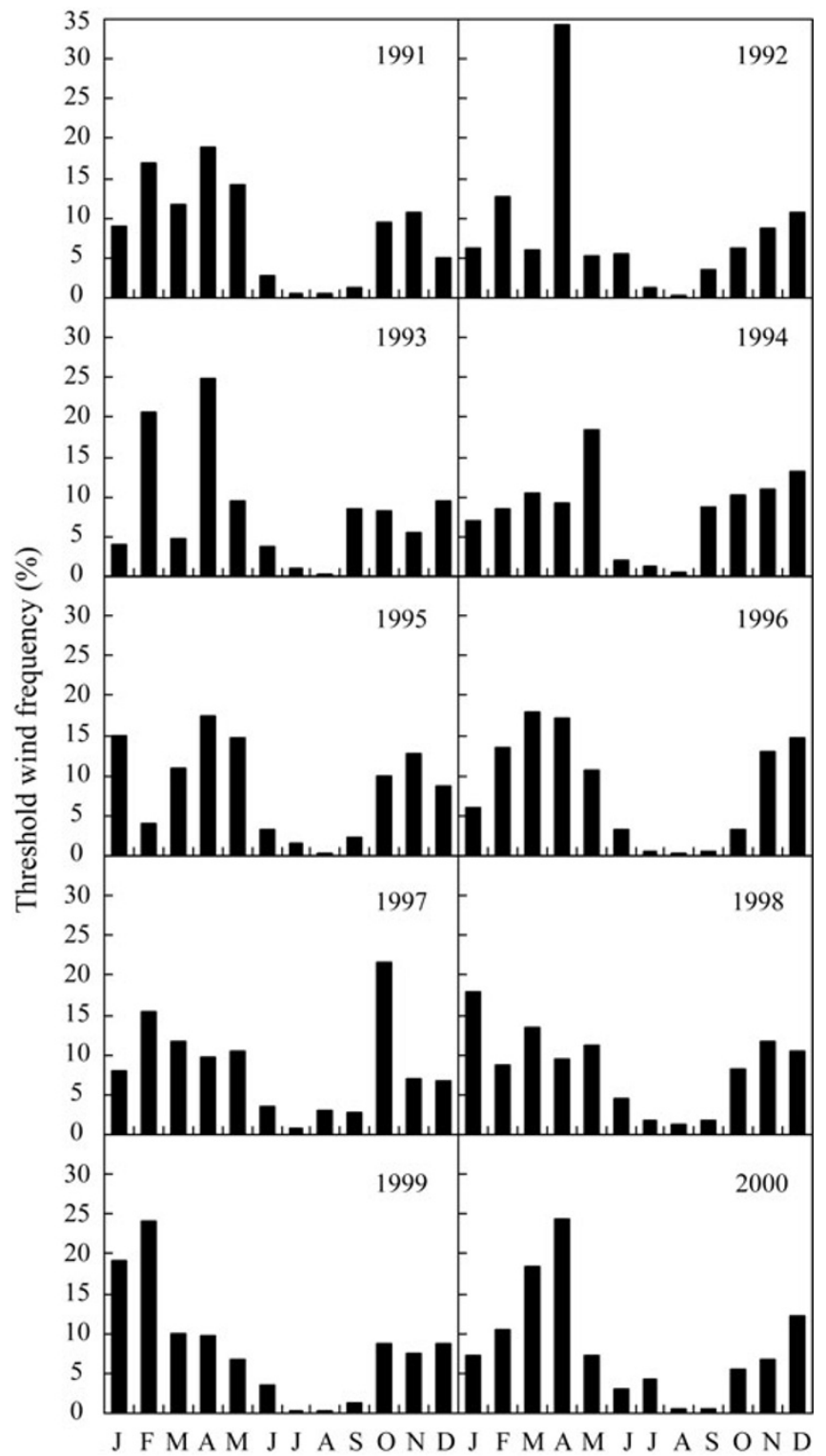

Figure 7. Percentage of erosive winds in every month from 1991 to 2000 at Fengning, Hebei Province

directions of the erosive winds determined the southeastward direction of sand- and dust storms originating from the arid and semiarid areas, which significantly affected the atmospheric environment of Beijing.

\subsubsection{Influence of Erosive Wind Frequency on Aeolian Sand Transport}

The annual quantity of aeolian sand transport on mobile sand surfaces was calculated from 1991 to 2000, based on the erosive wind speed, frequency, and Eq. 1. The average sand transport for the ten years was $33,424 \mathrm{~g} \mathrm{~cm}^{-1} \mathrm{a}^{-1}$, with a maximum of $64,080 \mathrm{~g} \mathrm{~cm}^{-1} \mathrm{a}^{-1}$ in 1995 and a minimum of $22,935 \mathrm{~g} \mathrm{~cm}^{-1} \mathrm{a}^{-1}$ in 1991. The quantity of $39,046 \mathrm{~g} \mathrm{~cm}^{-1} \mathrm{a}^{-1}$ in 2000 ranked third place (Figure 9). 

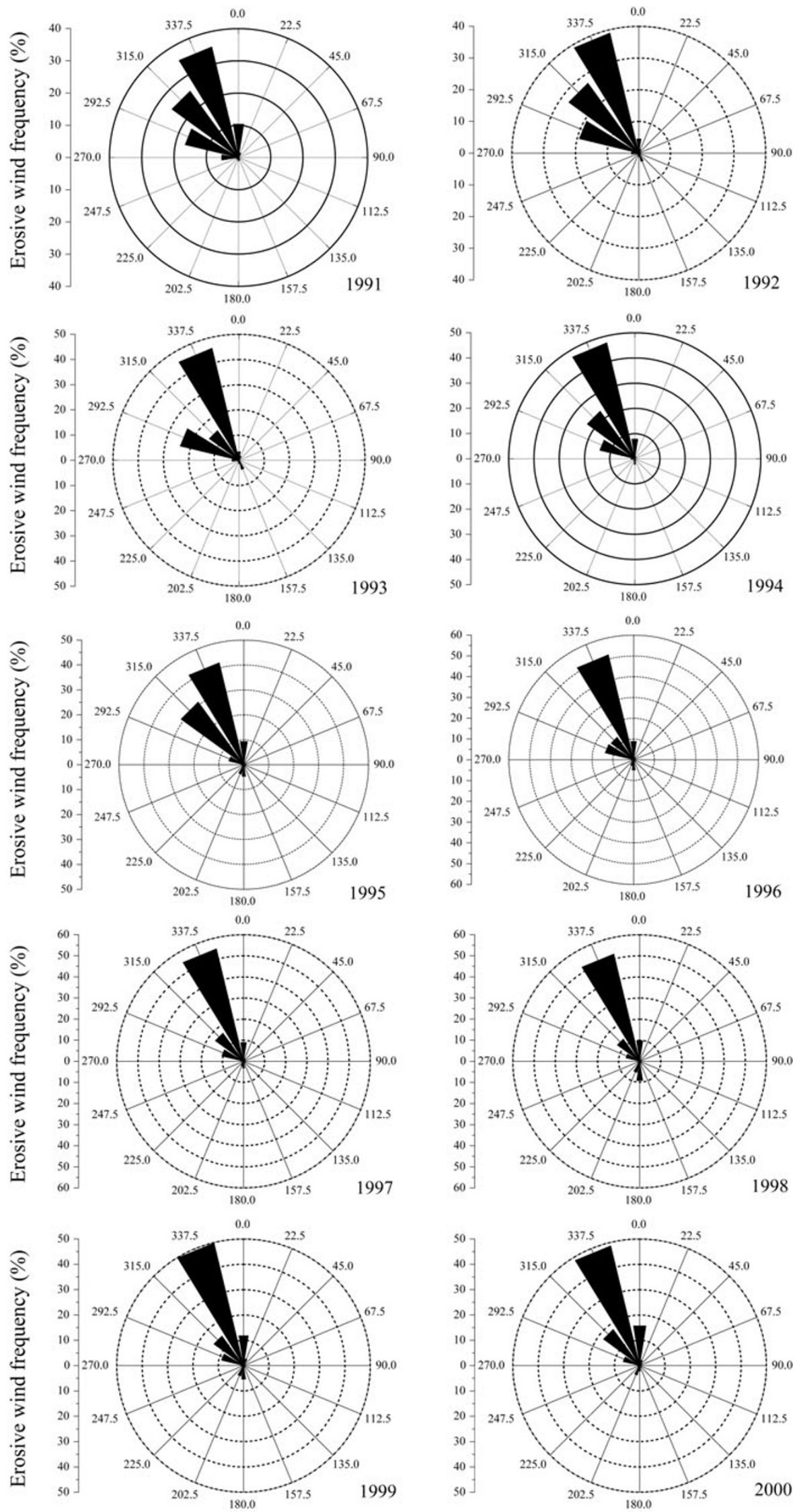

Figure 8. Frequency of erosive winds from different directions from 1991 to 2000 at Fengning, Hebei Province 


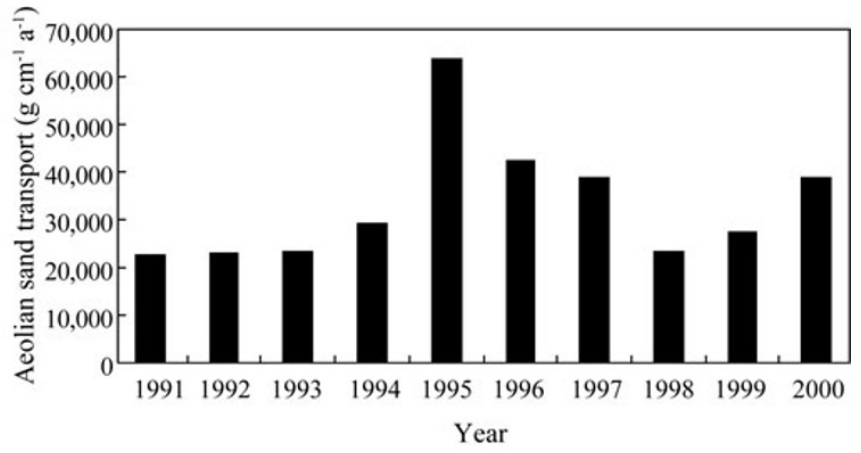

Figure 9. Aeolian sand transport on mobile sand surfaces from 1991 to 2000 in Fengning region

Figure 10 shows that erosive wind frequency $\left(f_{e}\right)$ had an obvious effect on aeolian sand transport $\left(Q_{s}\right)$ and their relationship could be expressed as:

$$
Q_{s}=9182.5 f_{e}-8787.5 \quad R^{2}=0.99
$$

There were also pronounced connections between strong wind days and aeolian sand transport on mobile dunes (Figure 11), and between strong wind days and erosive wind frequency (Figure 12). However, based on the 10-year data between 1991 and 2000, the influence of erosive wind frequency on aeolian sand transport cannot adequately explain the outburst of sandstorms in 2000.

\subsubsection{Climatic Index of Wind Erosion}

Research on wind erosion indicated that wind and precipitation are important climatic factors influencing aeolian sand processes. The rate of wind erosion is positively related to wind speed and its duration, while negatively related to soil moisture and vegetation cover (Fryrear 1985; Lancaster 1985). Due to complex interactions among the influencing

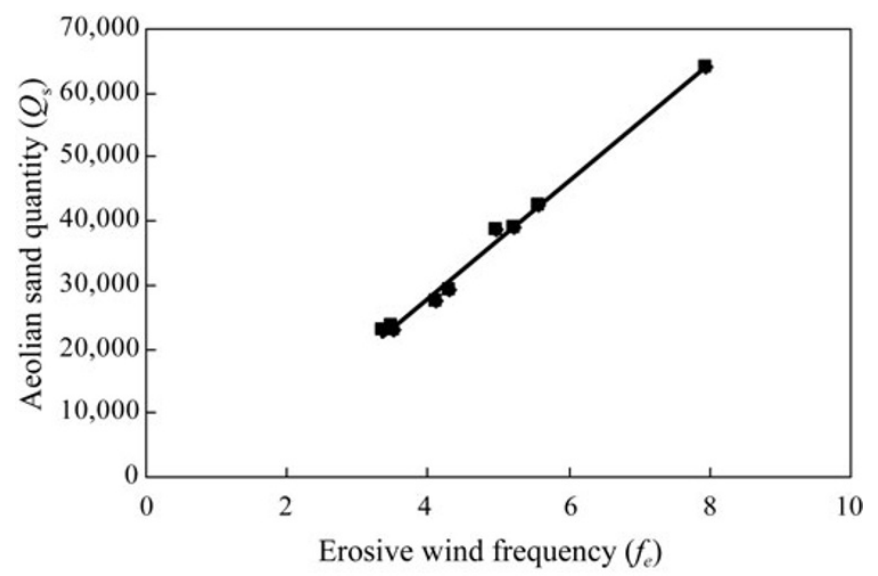

Figure 10. Relationship between erosive wind frequency $\left(f_{\mathrm{e}}\right)$ and aeolian sand quantity $\left(Q_{s}\right)$

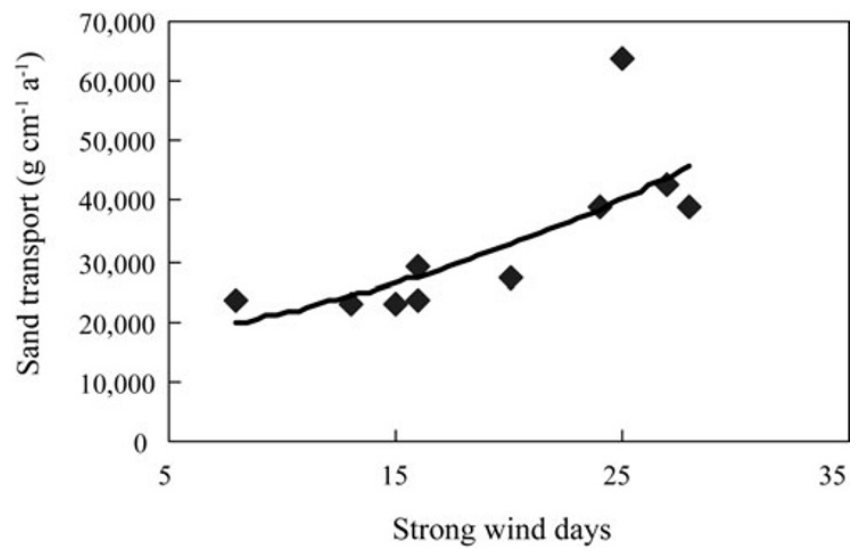

Figure 11. Relationship between aeolian sand transport on mobile dunes and strong wind days

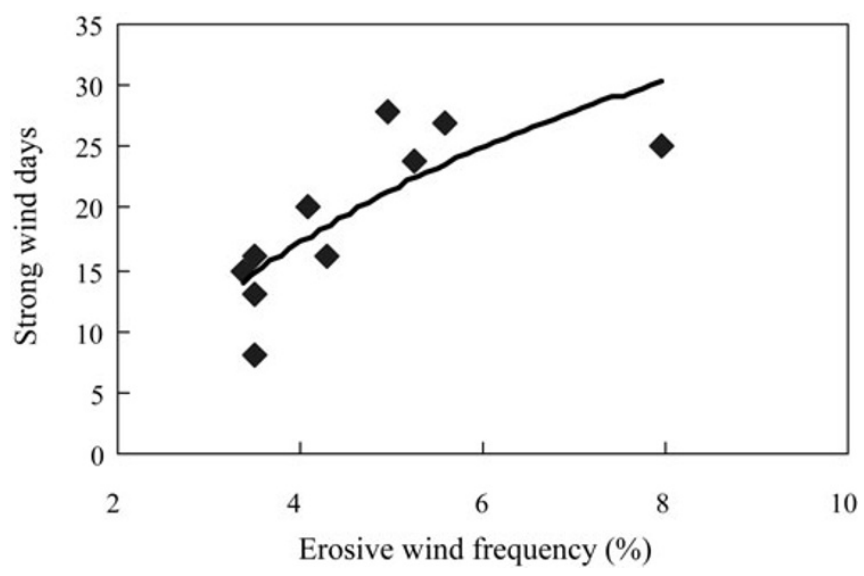

Figure 12. Relationship between erosive wind frequency and strong wind days

factors, it is difficult to determine the actual effect of multifactors on aeolian sand processes. Considering precipitation has both an effect on soil moisture and vegetation cover, we use precipitation and erosive wind frequency to set up

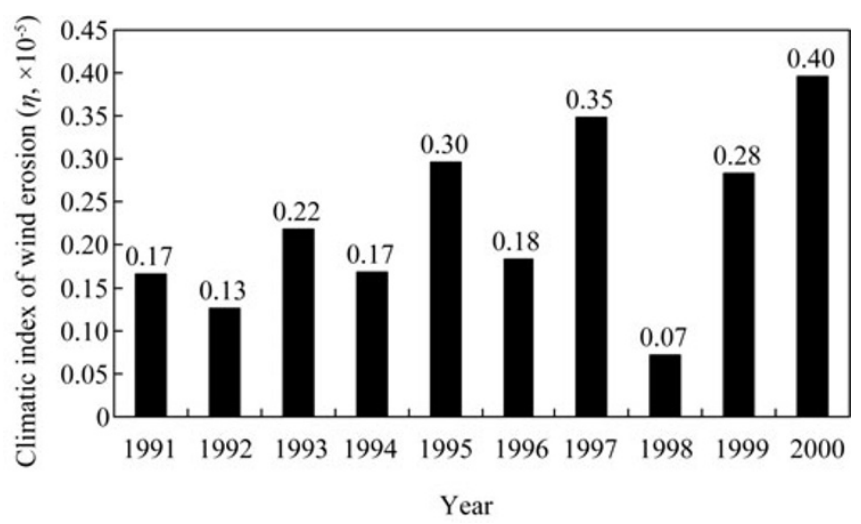

Figure 13. Climatic index of wind erosion from 1991 to 2000 


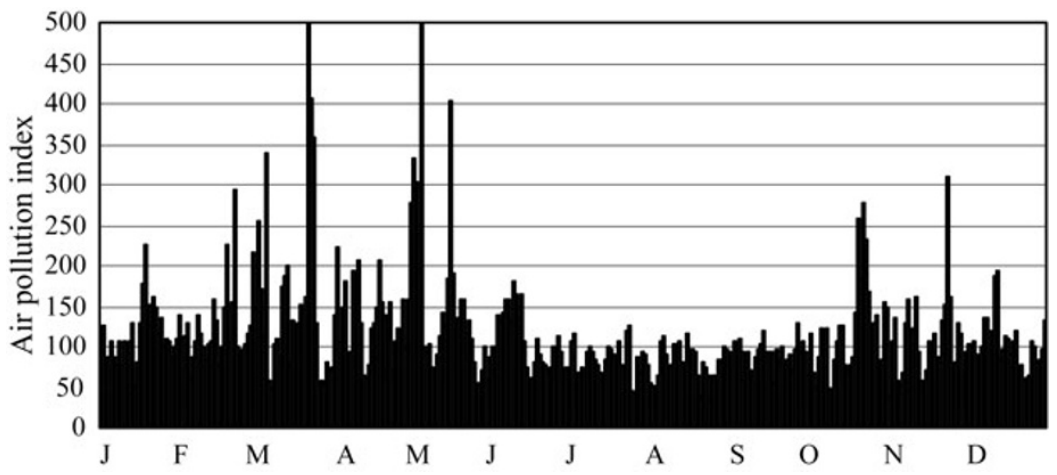

Figure 14. Air pollution index of every month in the representative year in Beijing

a multivariable climatic index to explain aeolian sand processes:

$$
\eta=f_{e} / r^{2}
$$

Where $\eta$ is the dimensionless climatic index of wind erosion, $f_{e}$ is the erosive wind frequency, and $r$ is precipitation.

The annual climatic index of wind erosion was calculated based on the erosive wind frequency and precipitation from 1991 to 2000 at the Fengning Station (Figure 13). The index indicated that the main factor that caused the outburst of sandand dust storms in 2000 might be the lasting drought from 1999 to 2000 , which gave rise to land desiccation, vegetation degradation, and land surface mobility, and finally led to the intensification of aeolian sand activities. Although the drought and sand- and dust storms in 2000 did not persist for as long as the dustbowl that occurred in the 1930s in the United States, their impact on the ecosystem and environment was widespread.

\section{Blown Sand and Dust Weather and Air Pollution in Beijing}

Blown sand and dust weather including sand- and dust storms and dust haze are hazardous occurrences with high frequencies from winter to spring in Beijing. Generally, 47 percent of the annual sand- and dust storm days, 50 percent of the blown sand days, and 76 percent of the dust haze days occurred in springtime. The air pollution index in Beijing is obviously affected by sand blown activities in spring (Figure 14).

\section{Conclusion}

Vegetation cover has an obvious effect on threshold velocity and sand transport rate. With the development of desertification, sand entrainment and dust emission can take place more easily from mobile sandy surfaces than semifixed and fixed sandy lands. Different soils have different sensitivity to cultivation disturbances. Erosive wind frequency has pronounced influence on sand transport. The dominant factors for the intensified sand- and dust storms in Beijing might be favorable wind conditions in combination with a lasting drought from 1999 to 2000, which led to land surface desiccation, vegetation degradation, and land surface mobility.

\section{Acknowledgments}

This work was supported by the National Science Foundation of China (41071331) and the Ministry of Education of China (v200801).

\section{References}

Duce, R. A., C. K. Unni, B. J. Ray, J. M. Prospero, and J. T. Merrill. 1980. Long-Range Atmospheric Transport of Soil Dust from Asia to the Tropical North Pacific: Temporal Variability. Science 209 (4464): $1522-24$.

Fryrear, D. W. 1985. Soil Cover and Wind Erosion. Transactions of the ASAE 28 (3): 781-84.

Lancaster, N. 1985. Winds and Sand Movements in the Namib Sand Sea. Earth Surface Processes and Landforms 10 (6): 607-19.

Liu, D. S. 1985. Loess and Environment. Beijing: Science Press (in Chinese).

Liu, L. Y. 1999. The Quantity and Intensity of Regional Aeolian Sand Erosion and Deposition: The Case of Shanxi-Shaanxi-Nei Monggol Region. Acta Geographica Sinica 54 (1): 59-68 (in Chinese).

Pye, K. 1987. Aeolian Dust and Dust Deposits. London: Academic Press.

Qiu, X. F., Y. Zeng, and Q. L. Miao. 2001. Temporal and Spatial Distribution as well as Tracks and Source Areas of Sand-Dust Storms in China. Acta Geographica Sinica 56 (3): 316-22.

Qu, J. J., N. Huang, W. Q. Ta, J. Q. Lei, Z. B. Dong, X. W. Liu, X. Xue, R. P. Zu, and K. C. Zhang. 2005. Structural Characteristics of Gobi Sand Drift and its Significance. Advances in Earth Science 20 (1): 19-23 (in Chinese, English summary).

von Richthofen, F. 1882. On the Origin of the Loess. Geological Magazine 9: 293-305.

Shi, P. J., P. Yan, S. Y. Gao, Y. M. Wang, S. Ha, and Y. J. Yu. 2000. Disaster of Sand and Dust Storms in China: Research Progress and Prospects. Journal of Natural Disaster 9 (3): 71-77 (in Chinese).

Stetler, L. D., and K. E. Saxton. 1996. Wind Erosion and PM Pmission $_{10}$ from Agricultural Fields on the Columbia Plateau. Earth Surface Processes and Landforms 21 (7): 673-85. 
Wu, Z. 1987. Aeolian Geomorphology. Beijing: Science Press (in Chinese).

Yang, G. S., X. M. Di, and Z. H. Huang. 1991. Desertification and its Control along the Great Wall to the North of the Loess Plateau. Beijing: Science Press (in Chinese).

Ye, D. Z., J. F. Chou, J. Y. Liu, Z. X. Zhang, Y. M. Wang, Z. J. Zhou, H. B. Ju, and H. Q. Huang. 2000. On the Causes of Sand and Dust Weather in the North of China and Countermeasures. Acta Geographica Sinica 55 (5): 513-21 (in Chinese).
Zhang, D. E. 1982. Analysis of Historical "Dust Rains." Chinese Science Bulletin 27 (5): 294-97 (in Chinese).

Zhao, Y., Z. P. Jin, P. J. Shi, and Y. C. Hao. 1989. Studies on Soil Erosion in Inner Mongolia. Beijing: Science Press (in Chinese).

Zhou, T. R., and L. S. Zhang. 1992. Holocene Environment Evolution and Prediction of the Farming-Pastoral Ecotone in China. Beijing: Geological Press (in Chinese).

Zhu, Z. D., and G. T. Chen. 1994. Sandy Desertification in China. Beijing: Science Press (in Chinese).

Open Access This article is distributed under the terms of the Creative Commons Attribution License which permits any use, distribution, and reproduction in any medium, provided the original author(s) and source are credited. 